\title{
Review Article \\ Essential Notes Regarding the Design of Functional siRNAs for Efficient Mammalian RNAi
}

\author{
Kumiko Ui-Tei, ${ }^{1}$ Yuki Naito, ${ }^{2}$ and Kaoru Saigo ${ }^{2}$ \\ ${ }^{1}$ Department of Biophysics and Biochemistry, Graduate School of Science and Undergraduate Program for Bioinformatics \\ and Systems Biology, School of Science, The University of Tokyo, 7-3-1 Hongo, Bunkyo-ku, Tokyo 113-0033, Japan \\ ${ }^{2}$ Department of Biophysics and Biochemistry, Graduate School of Science, The University of Tokyo, 7-3-1 Hongo, \\ Bunkyo-ku, Tokyo 113-0033, Japan
}

Received 25 January 2006; Accepted 17 April 2006

Short interfering RNAs (siRNAs) are widely used to bring about RNA interference (RNAi) in mammalian cells. Numerous siRNAs may be designed for any target gene though most of which would be incapable of efficiently inducing mammalian RNAi. Certain highly functional siRNAs designed for knockout of a particular gene may render unrelated endogenous genes nonfunctional. These major bottlenecks should be properly eliminated when RNAi technologies are employed for any experiment in mammalian functional genomics. This paper thus presents essential notes and findings regarding the proper choice of siRNA-sequence selection algorithms and web-based online software systems.

Copyright (c) 2006 Kumiko Ui-Tei et al. This is an open access article distributed under the Creative Commons Attribution License, which permits unrestricted use, distribution, and reproduction in any medium, provided the original work is properly cited.

\section{INTRODUCTION}

RNA interference (RNAi) is the process of nucleotide-sequence-specific post-transcriptional gene silencing [1-5]. In the case of lower eukaryotes such as Drosophila and Caenorhabditis elegans, long dsRNA may be used as an RNAi inducer [6-15], while, possibly owing to interferon response [16-20], short interfering RNA (siRNA), a Dicer digestion product of long dsRNA, is widely used for knocking down mammalian genes through RNAi [21-23]. Interferon response can be brought about even by siRNA transfection [24-28] and may be permitted in most cultured cell experiments, in which siRNA concentration is equal to or less than $100 \mathrm{nM}$ [29]. In therapeutic application, low siRNAdependent interferon response would be a matter of concern $[17,18]$.

Theoretically, (n-20) siRNAs targeting for a gene $\mathrm{n} b \mathrm{p}$ in length can be designed. In Drosophila, more than $90 \%$ of these siRNAs are capable of reducing target gene activity by more than $80 \%$ [29]. The design of siRNAs in the case of Drosophila as well as other lower eukaryotes would thus not involve any real difficulty. But about $80 \%$ of theoretically designable siRNAs would not be highly functional in the case of mammalian RNAi $[29,30]$. With certain target genes rich in GC, nonfunctional siRNAs may increase by $95 \%$ or more of the total designable siRNAs [Y N et al, unpublished].
Mismatched siRNA may occasionally inactivate genes other than the target, an undesired side effect designated as the "off-target effect" $[31,32]$. The molecular basis for this remains to be clarified [33] though mRNA cleavage, the climax of the RNAi reaction [34-38], requires a nearly strict nucleotide sequence identity between the mRNA target portion and sense strand (SS) of siRNA [33, 39]. Thus, at least some fraction of undesirable siRNAs, giving rise to the off-target effect through destabilization of mRNAs other than the target, may be eliminated by computer-based homology search [40-45].

In the design of highly functional siRNAs for mammalian RNAi, suitable sequence conditions or good algorithms for selection of highly functional siRNAs and good computer software suitable for genome-wide short-sequence homology search to minimize the off-target effect are indispensable.

Too many websites are available for functional siRNA search for mammalian RNAi as partly listed in Table 1. These websites may incorporate one or a few algorithms for functional siRNA selection previously determined based on biological validation data. Considerable mammalian RNAi data are presently available so that, in some websites, original algorithms may have been replaced with those modified to be more effective yet do not appear in scientific journals, thus making difficult the evaluation of individual website 
TABLE 1: siRNA search websites.

\begin{tabular}{|c|c|c|}
\hline Website & URL & Reference or company \\
\hline BLOCK-iT RNAi Designer & https://rnaidesigner.invitrogen.com/ & Invitrogen \\
\hline DEQOR & http://cluster-1.mpi-cbg.de/Deqor/deqor.html & [46] \\
\hline Gene specific siRNA selector & http://bioinfo.wistar.upenn.edu/siRNA/siRNA.htm & {$[47]$} \\
\hline OptiRNAi & http://bioit.dbi.udel.edu/rnai/ & {$[48]$} \\
\hline RNAi Central & http://katahdin.cshl.org:9331/RNAi_web/ & Hannon Lab \\
\hline RNAi Design & http://www.idtdna.com/Scitools/SciTools.aspx & Integrated DNA Technologies \\
\hline Sfold & http://sfold.wadsworth.org/ & {$[49]$} \\
\hline $\mathrm{SiDE}$ & http://side.bioinfo.ochoa.fib.es/ & {$[50]$} \\
\hline siDESIGN Center & http://www.dharmacon.com/sidesign/ & Dharmacon Research, Inc \\
\hline siDirect & http://design.RNAi.jp/ & {$[40]$} \\
\hline siRNA Design Software & http://www.cs.hku.hk/ sirna/ & {$[51]$} \\
\hline siRNA Design Tool & $\begin{array}{l}\text { http://www1.qiagen.com/Products/GeneSilencing/ } \\
\text { CustomSiRna/SiRnaDesigner.aspx }\end{array}$ & Qiagen \\
\hline siRNA Selection Server & http://jura.wi.mit.edu/bioc/siRNA/ & {$[52]$} \\
\hline siRNA Sequence Selector & http://bioinfo.clontech.com/rnaidesigner/ & Clontech \\
\hline siRNA Target Designer & http://www.promega.com/siRNADesigner/ & Promega \\
\hline siRNA Target Finder & http://www.genscript.com/rnai.html & [53] \\
\hline siRNA Target Finder & http://www.ambion.com/techlib/misc/siRNA_finder.html & Ambion \\
\hline siRNA Wizard & http://www.sirnawizard.com/ & InvivoGen \\
\hline siSearch & http://sisearch.cgb.ki.se/ & [42] \\
\hline TROD & http://www.cellbio.unige.ch/RNAi.html & {$[54]$} \\
\hline
\end{tabular}

reliability. Consequently, the present study directs attention to basic frameworks and some related application problems of algorithms for the selection of highly functional siRNAs.

\section{RNAi-INDUCING ACTIVITY AS AN INTRINSIC PROPERTY OF THE SIRNA SEQUENCE}

RNAi activity induced in mammalian cells is highly dependent on the particular sequence of siRNA used [29, 30] and may vary depending on transfected cell types or transfection efficiency. To examine these factors, various siRNAs targeting for the firefly luciferase gene (luc) were synthesized and transfected with luc encoding plasmid DNA into a variety of mammalian cell lines, which include human HeLa, HEK293, and colo205, Chinese hamster CHO-K1, and mouse E14TG2A ES cells [55]. The concentration of siRNA used in these experiments was 5$50 \mathrm{nM}$. siRNA-dependent RNAi activity was also examined in chicken embryos [29]. The transfection efficiency of colo205 is quite low and about 1/100 times as high as that of HeLa [55]. Neither difference in animal species from which cell lines or embryos were derived nor that in transfection efficiency had any significant effect on induced RNAi activity $[29,55]$. RNAi activity induced in mammalian and chicken cells upon siRNA transfection may thus be determined primarily by the transfected siRNA sequences themselves as far as RNAi due to $10-50 \mathrm{nM}$ siRNA is concerned.

\section{THREE BASIC ALGORITHMS FOR SELECTING FUNCTIONAL SIRNAS BASED ON BIOLOGICAL VALIDATION}

Many experiments have been conducted to clarify possible sequence requirements of functional siRNAs for mammalian RNAi [29, 56-61]. Only three representative algorithms, which may be widely used for functional siRNA search for mammalian RNAi, are presented and discussed in the following.

Algorithm 1. This algorithm was developed by Ui-Tei et al [29]. As shown in Figure 1(a1), all siRNAs satisfying the following four sequence conditions are defined as class I siRNAs in Algorithm 1: (1) the $5^{\prime}$ antisense-strand (AS) end, A or U, (2) the $5^{\prime}$ SS end, G or C, (3) the $5^{\prime}$-terminal one-third of AS, A/U-rich, and (4) a long G/C stretch, absent from the $5^{\prime}$ terminal two thirds of SS. Validation data obtained using luc as a target indicated all of 40 class I siRNAs arbitrarily chosen to be capable of reducing target gene activity by more than $70 \%$ [29]. All RNAi experiments were conducted at $50 \mathrm{nM}$ siRNA.

Algorithm 1 siRNAs with features completely the opposite to those of class I siRNAs except for condition (4) are defined as class III siRNAs (Figure 1(a2)). Validation indicated that all of 15 class III siRNAs arbitrarily chosen are incapable of inducing efficient mammalian RNAi [29]. Thus, most, if not all, class I siRNAs may possibly serve as siRNAs highly functional in mammalian cells. Class III siRNAs 


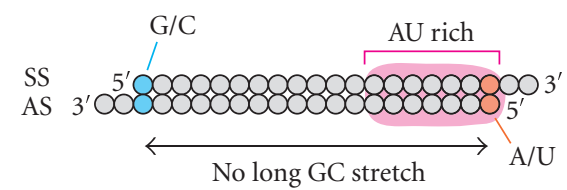

(a1) Class I

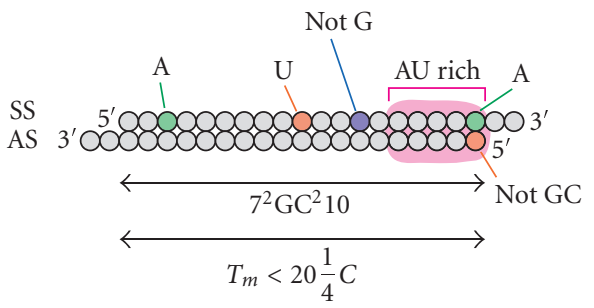

(b)

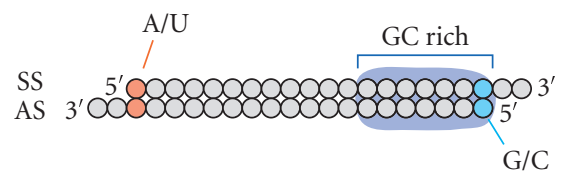

(a2) Class III

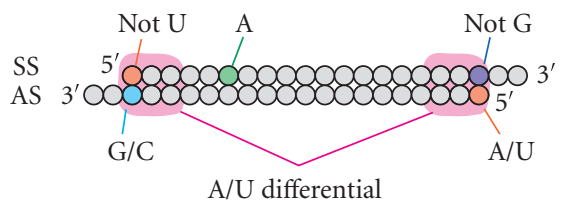

(c)

$100 \%=43747193$ targets in RefSeq, cds

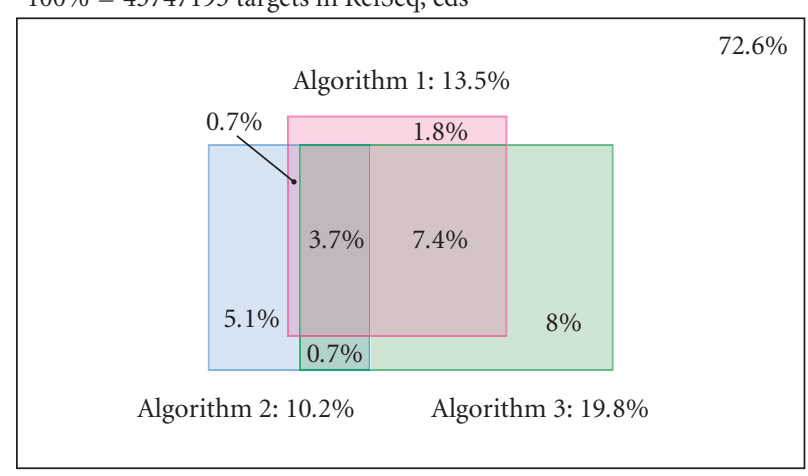

(d)

FIGURE 1: Three algorithms for siRNA design for functional RNAi in mammalian cells. (a) Algorithm 1. Highly functional class I siRNAs simultaneously satisfy the following four conditions: A/U at the $5^{\prime}$ AS end, G/C at the $5^{\prime}$ SS end, more than four A/U nucleotides in the $5^{\prime}$-terminal one-third of AS, and lacking a long G/C stretch in the $5^{\prime}$-terminal two-thirds of SS. Ineffective class III siRNAs possess features opposite to class I siRNAs. (b) Algorithm 2. There are 8 requirements for this algorithm: low G/C contents (30-52\%), three or more A/U at the five $3^{\prime}$-terminal base pairs of SS, low internal stability lacking stable inverted repeats, and base preferences at SS positions 3, 10, 13, and 19. (c) Algorithm 3. A/U content in the $5^{\prime}$ AS end should be higher than that in the $5^{\prime}$ SS end. Base preferences are also required at positions indicated. (d) Difference in functional siRNA prediction between three Algorithms, 1, 2, and 3. 43747193 siRNA sequences were collected from human RefSeq sequences and classified using three algorithms.

are nearly incapable of inducing effective mammalian RNAi. With the $l u c$, the total number of theoretically designable siRNAs is 1631 and class I siRNAs represent about 17\%, which is roughly identical to the percentage (25\%) of highly functional siRNAs estimated from validation data [29], class I siRNAs may thus constitute most, if not all, of siRNAs highly functional in mammalian RNAi.

Algorithm 2. This algorithm was proposed by Reynolds et al [59, Figure 1B] who carried out analysis of 180 siRNAs targeting mRNA of two genes and found the following characteristics associated with siRNA functionality: low G/C content, preference for low internal stability at the $3^{\prime}$-terminus of SS, and absence of inverted repeats. Furthermore, SS is presumed to preferably use A, U, and A at SS positions 3, 10, and 19 , respectively. The $5^{\prime}$ AS terminal should not be G/C. $\mathrm{G}$ may not be present at position 13 (Figure 1(b)). In more than half of class I siRNAs, there are no base preferences at position 3 and $10[29,55]$, so that Algorithms 1 and 2, respectively, may predict considerably different siRNA sets to be functional.

Algorithm 3. This algorithm was proposed by Amarzguioui and Prydz [60] who carried out statistical analysis on 46 siRNAs and found Algorithm 3 to require the following features for functional siRNAs. The $5^{\prime}$ AS terminus and its SS partner are A/U and the $5^{\prime}$ SS terminus and its AS partner, G/C. An opposite combination of terminal bases may give rise to inadequate functionality. These authors also found that there is asymmetry in siRNA duplex end stability; that is, the $\mathrm{A} / \mathrm{U}$ content differential for the three terminal nucleotides at both ends of the duplex may be considered essential to siRNA functionality. Furthermore, they noted A to prefer position 6 of functional siRNAs (Figure 1(c)), although only a small 
fraction of class I siRNAs is associated with A at SS position 6 [29].

To examine in greater detail, relationships among the three algorithms, that the percentage of siRNAs considered functional by Algorithm 1 (class I) can be repredicted as functional by Algorithms 2 or 3 or vice versa, was determined (see [55, Figure 1D]. Based on the three algorithms, total possible siRNA sequences $\left(4.4 \times 10^{7}\right)$ designed using RefSeq human sequences (version 11) were found to be nonfunctional by as much as $73 \%$. Class I siRNAs constituted $14 \%$ of the total theoretically predictable siRNAs, whereas Algorithms 2 and 3 , respectively, predict 10 and $20 \%$ as functional siRNAs. Nearly $90 \%$ of class I siRNAs could be repredicted as functional by Algorithm 2 or 3 or both. Eighty four percent of siRNAs simultaneously predicted as functional by Algorithms 2 and 3 could be repredicted as functional or class I siRNAs by Algorithm 1. More than 50\% of siRNAs predicted as functional by Algorithm 2 could not be predicted to be functional by Algorithm 3. Seventy seven percent of Algorithm 3 functional siRNAs could not be repredicted as functional by Algorithm 2. These findings may indicate that Algorithm 1 is capable of predicting the functionality of siRNAs more reliably than Algorithms 2 or 3.

\section{ALIGNMENT ALGORITHM FOR SHORT NUCLEOTIDE SEQUENCES}

Rapid homology comparison of the entire mRNA sequences with siRNA AS/SS sequences is indispensable for identifying off-target genes. BLAST [62] may not be a good software for making such comparison, since a number of off-target candidates are overlooked and too, considerable time is required for BLAST-based calculation. The Smith-Waterman local alignment algorithm [63] is accurate but time consuming to execute. Recently, Yamada and Morishita have developed a very rapid and accurate alignment algorithm for short nucleotide sequences [41] and this software can process 60 million siRNA sequences of 21 nucleotides in length in 10 hours when executed in parallel on ten inexpensive PCs. The hardware of Snøve Jr and Holen [64] provides similar performance although the number of processing units is not clearly specified. Websites using the Yamada-Morishita software or hardware of Snøve Jr and Holen should thus prove much more rapid and reliable compared to BLAST.

The base mismatch introduction studies indicate that transfected siRNAs occasionally cause phosphodiester-bond cleavage not only of the authentic mRNA target but also mutated targets with 1-2 base mismatches [33, 39]. But mutated targets with three or more mismatches may not undergo cleavage by transfection of the same siRNA [Y N et al, unpublished]. siRNAs less than $84(16 / 19 \times 100) \%$ homology in sequence to any part of total mRNAs other than the target should thus be used for RNAi, which would reduce the number of available functional siRNAs to $1 / 10$ of the input. That is, only $10 \%$ of class I siRNAs or less than $2 \%$ of total siRNAs theoretically designable using human RefSeq sequences becomes available in mammalian RNAi when off-target effects due to mRNA destability are considered. Computational analysis indicated that, even so few available siRNAs, at least one functional class I siRNA can be assigned to more than $99 \%$ of human mRNA sequences (RefSeq sequences) [ $\mathrm{Y} \mathrm{N}$ et al, unpublished].

miRNAs involved in posttranscriptional gene silencing through translational regulation [65-73] possess less homology with the target, indicating siRNAs with lesser homology in some cases to possibly be involved in some off-target reactions [74]. The elimination of a large number of siRNA with low homology to mRNAs other than the target may render genome-wide gene silencing in mammalian cells quite difficult. The simultaneous use of a few to several siRNAs targeting for an identical gene (target gene) may possibly solve this problem since, in most cases, off-target targets would not be identical to each other $[31,32]$.

\section{EXPERIMENTAL PARAMETERS POSSIBLY AFFECTING FUNCTIONALITY OF SIRNAs}

siRNA-mediated RNAi activity may vary significantly depending on not only the particular siRNA sequence but also parameters such as siRNA concentration, duration of siRNA exposure, and possibly target mRNA concentration and secondary structure within cells $[29,75]$. Functional siRNAs in some cases have actually been found to induce maximum RNAi activity 1 day after transfection, whereas other siRNAs to express maximum activity on 2 or 3 days following transfection. Usually, functional-siRNA-dependent RNAi persists 1-2 weeks, whereas virtually no RNAi is induced within cells even after a long incubation with nonfunctional siRNAs. Class I siRNAs, capable of inducing highly functional RNAi when transfected at $50 \mathrm{nM}$, were considerably heterogeneous in capability of bringing about RNAi when used for 1-day transfection at the concentration of $50 \mathrm{pM}$ (see [29] by Ui-Tei et al). Reduction in target gene activity varied from 20 to $60 \%$ depending on the sequences of class I siRNAs used. Thus, additional sequence conditions may possibly be found so as to define a subclass of class I with more functionality but in such a case, nearly complete genome-wide gene silencing might no longer be possible.

Recently, Kim et al [76] showed that a 27 bp long dsRNA with blunt ends is much greater in functionality than $21 \mathrm{bp}$ long siRNA and suggested that short Dicer substrate dsRNA may be generally much more functional compared to authentic siRNAs $21 \mathrm{bp}$ long. However, it was subsequently found that this is not a general feature of $27 \mathrm{bp}$ long bluntended dsRNA [77]. In the absence of $3^{\prime}$ overhang, Dicer digests dsRNA uncontrollably, generating many products varying in length, most of which may not be as functional as $21 \mathrm{bp}$ long highly functional siRNAs [77]. RNAi-inducing activity would thus appear to depend primarily on the presence of considerable highly functional siRNAs in the digestion products and so, consequently, $27 \mathrm{bp}$ long blunt-end dsRNA would not be necessarily a good choice for highly efficient RNAi. 


\section{SIRNA-OLIGOMER-DEPENDENT RNAi IN MAMMALIAN CELLS}

Long dsRNA possessing 2-nucleotide 3' overhangs at both ends is cleaved by Dicer from these ends to generate siRNAs having definite nucleotide sequences [28, 77-80]. Thus, should nearly all siRNAs produced by Dicer digestion belong to class I and the interferon response due to dsRNAs equivalent in length to siRNA oligomers not being significant, the induction of effective multiple-gene knockout in mammalian cells may occur with transfection of siRNA oligomers and this was recently found to be the case [28]. Through use of class-I-siRNA oligomers multiple-target gene knockout was clearly shown to take place.

\section{DNA/shRNA-MEDIATED RNAi}

RNAi can be induced by introducing DNA encoding both SS and AS of siRNA into mammalian cells. Both RNA polymerase III and II promoters, respectively, are used to express short hairpin RNA (shRNA) and longer RNA including shRNA sequence in the middle [81-90]. The primary transcript of RNA polymerase III is a mixture of shRNAs with two to several consecutive U's at its $3^{\prime}$ overhang [8188]. Dicer cleavage sites of shRNAs vary depending on the length of $3^{\prime}$ overhangs [89] and accordingly, several different species of siRNAs are expected to be generated from shRNAs transcribed by polymerase III [88]. Thus, the presence of highly functional siRNAs in these Dicer digestion products is required for successful RNAi due to a polymerase-III-based system. In addition, four consecutive U's or A's should not be included in the nonoverhang sequences of AS and SS, respectively, since these sequences stimulate premature termination of polymerase-III-dependent transcription [88].

In polymerase II-driven expression systems, the primary transcript is long polyadenylated RNA (pri-miRNAlike RNA), which is recognized and cleaved by the nuclear microprocessor complex [91, 92]. This complex contains Drosha, an RNase III-type RNase that cleaves the primiRNA-like RNA to generate shRNA with a 2-nucleotide 3' overhang [93]. The shRNA thus produced is converted mainly to two overlapping siRNAs through Dicer digestion (see [28]), indicating that successful RNAi requires the involvement of highly functional siRNAs in these siRNA products.

\section{POSSIBLE MOLECULAR BASES OF ASYMMETRIC SEQUENCE REQUIREMENTS IN FUNCTIONAL SIRNAS}

Each mammalian Argonaute proteins (eIF2Cs) is comprised of a PRP motif and two domains: PAZ and PIWI [94]. Structural analysis of the Argonaute protein crystals from Pyrococcus farious indicated that the PIWI domain has essentially the same three-dimensional structure as ribonuclease $H$ and that Argonaute may function as a slicer of mRNA [95]. PAZ and PIWI domains may recognize separately two ends of siRNA. The crystal structure of the PAZ domain from human
Argonaute 1 suggested that the PAZ domain is anchored to the 2-nucleotide $3^{\prime}$ overhang of the siRNA duplex [96]. The PIWI domain from Archaeoglobus fulgidus contains a highly conserved metal-binding site that may recognize the $5^{\prime}$ nucleotide of AS of siRNA in a manner not dependent on sequence [97].

Algorithms 1 and 3 predict functional siRNAs to possess $\mathrm{A} / \mathrm{U}$ and $\mathrm{G} / \mathrm{C}$ at the $5^{\prime} \mathrm{AS}$ and $\mathrm{SS}$ ends, respectively $[29,55,60]$. The GC pair is thermodynamically much more stable than the AU pair and thus, differences in stability in terminal base pair of the siRNA duplex may determine terminal sequence preference in highly functional and nonfunctional siRNAs, most probably by stimulating asymmetric binding of PIWI and PAZ domains to siRNA ends.

The $5^{\prime}$-terminal one-third of AS of functional class I siRNAs is A/U-rich, possibly due to preferable siRNA unwinding from its AS end $[29,56]$. A one-step motor function of the putative siRNA helicase may unwind several base pairs from the A/U-rich siRNA end to stimulate formation of active RISC lacking SS of siRNA. Should this be the case, the introduction of base mismatches into the $3^{\prime}$-terminal third SS of siRNA may significantly increase the induced RNAi activity. Studies with Drosophila extracts showed a significant base-mismatch-dependent increase in RISC formation [56]. But, to date there are no data clearly confirm this in mammalian cultured cell experiments. Recently a part of RISC has been shown to be activated through cleavage of SS of siRNA at its center [98]. The presence of base mismatches in SS might be unfavorable to SS cleavage and this negative effect might partially prevent siRNA from being unwound.

\section{ACKNOWLEDGMENTS}

This work was partially supported by Special Coordination Fund for Promoting Science and Technology to K S, and Grants from the Ministries of Education, Culture, Sports, Science and Technology of Japan to K S and K U-T.

\section{REFERENCES}

[1] Fire A, Xu S, Montgomery MK, Kostas SA, Driver SE, Mello CC. Potent and specific genetic interference by doublestranded RNA in caenorhabditis elegans. Nature. 1998;391 (6669):806-811.

[2] Dykxhoorn DM, Novina CD, Sharp PA. Killing the messenger: short RNAs that silence gene expression. Nature Reviews. Molecular Cell Biology. 2003;4(6):457-467.

[3] Mello CC, Conte D Jr. Revealing the world of RNA interference. Nature. 2004;431(7006):338-342.

[4] Meister G, Tuschl T. Mechanisms of gene silencing by doublestranded RNA. Nature. 2004;431(7006):343-349.

[5] Dykxhoorn DM, Palliser D, Lieberman J. The silent treatment: siRNAs as small molecule drugs. Gene Therapy. 2006;13(6): 541-552.

[6] Ui-Tei K, Zenno S, Miyata Y, Saigo K. Sensitive assay of RNA interference in Drosophila and Chinese hamster cultured cells using firefly luciferase gene as target. FEBS Letters. 2000;479 (3):79-82.

[7] Barstead R. Genome-wide RNAi. Current Opinion in Chemical Biology. 2001;5(1):63-66. 
[8] Maeda I, Kohara Y, Yamamoto M, Sugimoto A. Large-scale analysis of gene function in Caenorhabditis elegans by highthroughput RNAi. Current Biology. 2001;11(3):171-176.

[9] Ueda R. RNAi: a new technology in the post-genomic sequencing era. Journal of Neurogenetics. 2001;15(3-4):193-204.

[10] Ashrafi K, Chang FY, Watts JL, et al. Genome-wide RNAi analysis of Caenorhabditis elegans fat regulatory genes. Nature. 2003;421(6920):268-272.

[11] Boutros M, Kiger AA, Armknecht S, et al. Genome-wide RNAi analysis of growth and viability in Drosophila cells. Science. 2004;303(5659):832-835.

[12] Carpenter AE, Sabatini DM. Systematic genome-wide screens of gene function. Nature Reviews. Genetics. 2004;5(1):11-22.

[13] Cheng LW, Viala JPM, Stuurman N, Wiedemann U, Vale RD, Portnoy DA. Use of RNA interference in Drosophila S2 cells to identify host pathways controlling compartmentalization of an intracellular pathogen. Proceedings of the National Academy of Sciences of the United States of America. 2005;102 (38):13646-13651.

[14] Nybakken K, Vokes SA, Lin T-Y, McMahon AP, Perrimon N. A genome-wide RNA interference screen in Drosophila melanogaster cells for new components of the Hh signaling pathway. Nature Genetics. 2005;37(12):1323-1332.

[15] Kim JK, Gabel HW, Kamath RS, et al. Functional genomic analysis of RNA interference in C. elegans. Science. 2005;308 (5725):1164-1167.

[16] Stark GR, Kerr IM, Williams BRG, Silverman RH, Schreiber RD. How cells respond to interferons. Annual Review of Biochemistry. 1998;67:227-264.

[17] Zhou H-S, Liu D-P, Liang C-C. Challenges and strategies: the immune responses in gene therapy. Medicinal Research Reviews. 2004;24(6):748-761.

[18] Karpala AJ, Doran TJ, Bean AGD. Immune responses to dsRNA: implications for gene silencing technologies. Immunology and Cell Biology. 2005;83(3):211-216.

[19] de Veer MJ, Sledz CA, Williams BRG. Detection of foreign RNA: implications for RNAi. Immunology and Cell Biology. 2005;83(3):224-228.

[20] Marques JT, Williams BRG. Activation of the mammalian immune system by siRNAs. Nature Biotechnology. 2005;23 (11):1399-1405.

[21] Elbashir SM, Lendeckel W, Tuschl T. RNA interference is mediated by 21 - and 22-nucleotide RNAs. Genes and Development. 2001;15(2):188-200.

[22] Elbashir SM, Harborth J, Lendeckel W, Yalcin A, Weber K, Tuschl T. Duplexes of 21-nucleotide RNAs mediate RNA interference in cultured mammalian cells. Nature. 2001;411 (6836):494-498.

[23] Elbashir SM, Martinez J, Patkaniowska A, Lendeckel W, Tuschl T. Functional anatomy of siRNAs for mediating efficient RNAi in Drosophila melanogaster embryo lysate. EMBO Journal. 2001;20(23):6877-6888.

[24] Sledz CA, Holko M, de Veer MJ, Silverman RH, Williams BRG. Activation of the interferon system by short-interfering RNAs. Nature Cell Biology. 2003;5(9):834-839.

[25] Sioud M. Induction of inflammatory cytokines and interferon responses by double-stranded and single-stranded siRNAs is sequence-dependent and requires endosomal localization. Journal of Molecular Biology. 2005;348(5):1079-1090.

[26] Hornung V, Guenthner-Biller M, Bourquin C, et al. Sequencespecific potent induction of IFN- $\alpha$ by short interfering RNA in plasmacytoid dendritic cells through TLR7. Nature Medicine. 2005;11(3):263-270.
[27] Judge AD, Sood V, Shaw JR, Fang D, McClintock K, MacLachlan I. Sequence-dependent stimulation of the mammalian innate immune response by synthetic siRNA. Nature Biotechnology. 2005;23(4):457-462.

[28] Ui-Tei K, Zenno S, Juni A, Saigo K. RNAi induced in mammalian and Drosophila cells via transfection of dimers and trimers of short interfering RNA. Journal of RNAi and Gene Silencing. 2005;1(2):79-87.

[29] Ui-Tei K, Naito Y, Takahashi F, et al. Guidelines for the selection of highly effective siRNA sequences for mammalian and chick RNA interference. Nucleic Acids Research. 2004;32(3):936-948.

[30] Holen T, Amarzguioui M, Wiiger MT, Babaie E, Prydz H. Positional effects of short interfering RNAs targeting the human coagulation trigger tissue factor. Nucleic Acids Research. 2002;30(8):1757-1766.

[31] Jackson AL, Bartz SR, Schelter J, et al. Expression profiling reveals off-target gene regulation by RNAi. Nature Biotechnology. 2003;21(6):635-637.

[32] Jackson AL, Linsley PS. Noise amidst the silence: off-target effects of siRNAs? Trends in Genetics. 2004;20(11):521-524.

[33] Du Q, Thonberg H, Wang J, Wahlestedt C, Liang Z. A systematic analysis of the silencing effects of an active siRNA at all single-nucleotide mismatched target sites. Nucleic Acids Research. 2005;33(5):1671-1677.

[34] Martinez J, Patkaniowska A, Urlaub H, Lührmann R, Tuschl T. Single-stranded antisense siRNAs guide target RNA cleavage in RNAi. Cell. 2002;110(5):563-574.

[35] Song J-J, Smith SK, Hannon GJ, Joshua-Tor L. Crystal structure of Argonaute and its implications for RISC slicer activity. Science. 2004;305(5689):1434-1437.

[36] Liu J, Carmell MA, Rivas FV, et al. Argonaute2 is the catalytic engine of mammalian RNAi. Science. 2004;305(5689):14371441.

[37] Parker JS, Roe SM, Barford D. Structural insights into mRNA recognition from a PIWI domain-siRNA guide complex. $\mathrm{Na}$ ture. 2005;434(7033):663-666.

[38] Miyoshi K, Tsukumo H, Nagami T, Siomi H, Siomi MC. Slicer function of Drosophila Argonautes and its involvement in RISC formation. Genes and Development. 2005;19(23):28372848.

[39] Abdelgany A, Wood M, Beeson D. Allele-specific silencing of a pathogenic mutant acetylcholine receptor subunit by RNA interference. Human Molecular Genetics. 2003;12(20):26372644.

[40] Naito Y, Yamada T, Ui-Tei K, Morishita S, Saigo K. siDirect: highly effective, target-specific siRNA design software for mammalian RNA interference. Nucleic Acids Research. 2004; 32:W124-W129.

[41] Yamada T, Morishita S. Accelerated off-target search algorithm for siRNA. Bioinformatics. 2005;21(8):1316-1324.

[42] Chalk AM, Warfinge RE, Georgii-Hemming P, Sonnhammer ELL. siRNAdb: a database of siRNA sequences. Nucleic Acids Research. 2005;33:D131-D134.

[43] Boese Q, Leake D, Reynolds A, et al. Mechanistic insights aid computational short interfering RNA design. Methods in Enzymology. 2005;392:73-96.

[44] Qiu S, Adema CM, Lane T. A computational study of offtarget effects of RNA interference. Nucleic Acids Research. 2005;33(6):1834-1847.

[45] Naito Y, Yamada T, Matsumiya T, Ui-Tei K, Saigo K, Morishita S. dsCheck: highly sensitive off-target search software for double-stranded RNA-mediated RNA interference. Nucleic Acids Research. 2005;33(suppl 2):W589-W591. 
[46] Henschel A, Buchholz F, Habermann B. DEQOR: a web-based tool for the design and quality control of siRNAs. Nucleic Acids Research. 2004;32:W113-W120.

[47] Levenkova N, Gu Q, Rux JJ. Gene specific siRNA selector. Bioinformatics. 2004;20(3):430-432.

[48] Cui W, Ning J, Naik UP, Duncan MK. OptiRNAi, an RNAi design tool. Computer Methods and Programs in Biomedicine. 2004;75(1):67-73.

[49] Ding Y, Chan CY, Lawrence CE. Sfold web server for statistical folding and rational design of nucleic acids. Nucleic Acids Research. 2004;32:W135-W141.

[50] Santoyo J, Vaquerizas JM, Dopazo J. Highly specific and accurate selection of siRNAs for high-throughput functional assays. Bioinformatics. 2005;21(8):1376-1382.

[51] Yiu SM, Wong PWH, Lam TW, et al. Filtering of ineffective siRNAs and improved siRNA design tool. Bioinformatics. 2005;21(2):144-151.

[52] Yuan B, Latek R, Hossbach M, Tuschl T, Lewitter F. siRNA selection server: an automated siRNA oligonucleotide predicition server. Nucleic Acids Research. 2004;32:W130-W134.

[53] Wang L, Mu FY. A web-based design center for vector-based siRNA and siRNA cassette. Bioinformatics. 2004;20(11):18181820.

[54] Dudek P, Picard D. TROD: T7 RNAi oligo designer. Nucleic Acids Research. 2004;32:W121-W123.

[55] Ui-Tei K, Naito Y, Saigo K. Guidelines for selection of effective short-interfering RNA sequences for functional genomics. Methods in Molecular Biology. 2006;2:201-216.

[56] Schwarz DS, Hutvágner G, Du T, Xu Z, Aronin N, Zamore PD. Asymmetry in the assembly of the RNAi enzyme complex. Cell. 2003;115(2):199-208.

[57] Khvorova A, Reynolds A, Jayasena SD. Functional siRNAs and miRNAs exhibit strand bias. Cell. 2003;115(2):209-216.

[58] Pancoska P, Moravek Z, Moll UM. Efficient RNA interference depends on global context of the target sequence: quantitative analysis of silencing efficiency using Eulerian graph representation of siRNA. Nucleic Acids Research. 2004;32(4):14691479.

[59] Reynolds A, Leake D, Boese Q, Scaringe S, Marshall WS, Khvorova A. Rational siRNA design for RNA interference. $\mathrm{Na}$ ture Biotechnology. 2004;22(3):326-330.

[60] Amarzguioui M, Prydz H. An algorithm for selection of functional siRNA sequences. Biochemical and Biophysical Research Communications. 2004;316(4):1050-1058.

[61] Jagla B, Aulner N, Kelly PD, et al. Sequence characteristics of functional siRNAs. RNA. 2005;11(6):864-872.

[62] Altschul SF, Gish W, Miller W, Myers EW, Lipman DJ. Basic local alignment search tool. Journal of Molecular Biology. 1990;215(3):403-410.

[63] Smith TF, Waterman MS. Identification of common molecular subsequences. Journal of Molecular Biology. 1981;147(1):195197.

[64] Snøve O Jr, Holen T. Many commonly used siRNAs risk offtarget activity. Biochemical and Biophysical Research Communications. 2004;319(1):256-263.

[65] Lagos-Quintana M, Rauhut R, Lendeckel W, Tuschl T. Identification of novel genes coding for small expressed RNAs. Science. 2001;294(5543):853-858.

[66] Ambros V. microRNAs: tiny regulators with great potential. Cell. 2001;107(7):823-826.

[67] McManus MT, Sharp PA. Gene silencing in mammals by small interfering RNAs. Nature Reviews Genetics. 2002;3(10):737747.
[68] Ambros V, Bartel B, Bartel DP, et al. A uniform system for microRNA annotation. RNA. 2003;9(3):277-279.

[69] He L, Hannon GJ. MicroRNAs: small RNAs with a big role in gene regulation. Nature Reviews Genetics. 2004;5(7):522-531.

[70] Croce CM, Calin GA. miRNAs, cancer, and stem cell division. Cell. 2005;122(1):6-7.

[71] Sontheimer EJ, Carthew RW. Silence from within: endogenous siRNAs and miRNAs. Cell. 2005;122(1):9-12.

[72] Sullivan CS, Ganem D. MicroRNAs and viral infection. Molecular Cell. 2005;20(1):3-7.

[73] Kosik KS, Krichevsky AM. The elegance of the microRNAs: a neuronal perspective. Neuron. 2005;47(6):779-782.

[74] Lin X, Ruan X, Anderson MG, et al. siRNA-mediated off-target gene silencing triggered by a $7 \mathrm{nt}$ complementation. Nucleic Acids Research. 2005;33(14):4527-4535.

[75] Omi K, Tokunaga K, Hohjoh H. Long-lasting RNAi activity in mammalian neurons. FEBS Letters. 2004;558(1-3):89-95.

[76] Kim D-H, Behlke MA, Rose SD, Chang M-S, Choi S, Rossi JJ. Synthetic dsRNA Dicer substrates enhance RNAi potency and efficacy. Nature Biotechnology. 2004;23(2):222-226.

[77] Rose SD, Kim D-H, Amarzguioui M, et al. Functional polarity is introduced by Dicer processing of short substrate RNAs. Nucleic Acids Research. 2005;33(13):4140-4156.

[78] Zhang H, Kolb FA, Brondani V, Billy E, Filipowicz W. Human Dicer preferentially cleaves dsRNAs at their termini without a requirement for ATP. EMBO Journal. 2002;21(21):5875-5885.

[79] Zhang H, Kolb FA, Jaskiewicz L, Westhof E, Filipowicz W. Single processing center models for human Dicer and bacterial RNase III. Cell. 2004;118(1):57-68.

[80] Vermeulen A, Behlen L, Reynolds A, et al. The contributions of dsRNA structure to Dicer specificity and efficiency. RNA. 2005;11(5):674-682.

[81] Brummelkamp TR, Bernards R, Agami R. A system for stable expression of short interfering RNAs in mammalian cells. Science. 2002;296(5567):550-553.

[82] Sui G, Soohoo C, Affar EB, et al. A DNA vector-based RNAi technology to suppress gene expression in mammalian cells. Proceedings of the National Academy of Sciences of the United States of America. 2002;99(8):5515-5520.

[83] Paddison PJ, Caudy AA, Hannon GJ. Stable suppression of gene expression by RNAi in mammalian cells. Proceedings of the National Academy of Sciences of the United States of America. 2002;99(3):1443-1448.

[84] Yu J-Y, DeRuiter SL, Turner DL. RNA interference by expression of short-interfering RNAs and hairpin RNAs in mammalian cells. Proceedings of the National Academy of Sciences of the United States of America. 2002;99(9):6047-6052.

[85] Lee NS, Dohjima T, Bauer G, et al. Expression of small interfering RNAs targeted against HIV-1 rev transcripts in human cells. Nature Biotechnology. 2002;20(5):500-505.

[86] Paul CP, Good PD, Winer I, Engelke DR. Effective expression of small interfering RNA in human cells. Nature Biotechnology. 2002;20(5):505-508.

[87] McManus MT, Petersen CP, Haines BB, Chen J, Sharp PA. Gene silencing using micro-RNA designed hairpins. RNA. 2002;8(6):842-850.

[88] Shi Y. Mammalian RNAi for the masses. Trends in Genetics. 2003;19(1):9-12.

[89] Silva JM, Li MZ, Chang K, et al. Second-generation shRNA libraries covering the mouse and human genomes. Nature Genetics. 2005;37(11):1281-1288.

[90] Stegmeier F, Hu G, Rickles RJ, Hannon GJ, Elledge SJ. A lentiviral microRNA-based system for single-copy polymerase II-regulated RNA interference in mammalian cells. Proceedings 
of the National Academy of Sciences of the United States of America. 2005;102(37):13212-13217.

[91] Gregory RI, Yan K-P, Amuthan G, et al. The microprocessor complex mediates the genesis of microRNAs. Nature. 2004;432 (7014):235-240.

[92] Denli AM, Tops BBJ, Plasterk RHA, Ketting RF, Hannon GJ. Processing of primary microRNAs by the microprocessor complex. Nature. 2004;432(7014):231-235.

[93] Lee Y, Ahn C, Han J, et al. The nuclear RNase III Drosha initiates microRNA processing. Nature. 2003;425(6956):415-419.

[94] Doi N, Zenno S, Ueda R, Ohki-Hamazaki H, Ui-Tei K, Saigo K. Short-interfering-RNA-mediated gene silencing in mammalian cells requires Dicer and eIF2C translation initiation factors. Current Biology. 2003;13(1):41-46.

[95] Song J-J, Smith SK, Hannon GJ, Joshua-Tor L. Crystal structure of Argonaute and its implications for RISC slicer activity. Science. 2004;305(5689):1434-1437.

[96] Ma J-B, Ye K, Patel DJ. Structural basis for overhang-specific small interfering RNA recognition by the PAZ domain. Nature. 2004;429(6989):318-322.

[97] Ma J-B, Yuan Y-R, Meister G, Pei Y, Tuschl T, Patel DJ. Structural basis for $5^{\prime}$-end-specific recognition of guide RNA by the A. fulgidus Piwi protein. Nature. 2005;434(7033):666-670.

[98] Leuschner PJ, Ameres SL, Kueng S, Martinez J. Cleavage of the siRNA passenger strand during RISC assembly in human cells. EMBO Reports. 2006;7(3):314-320. 

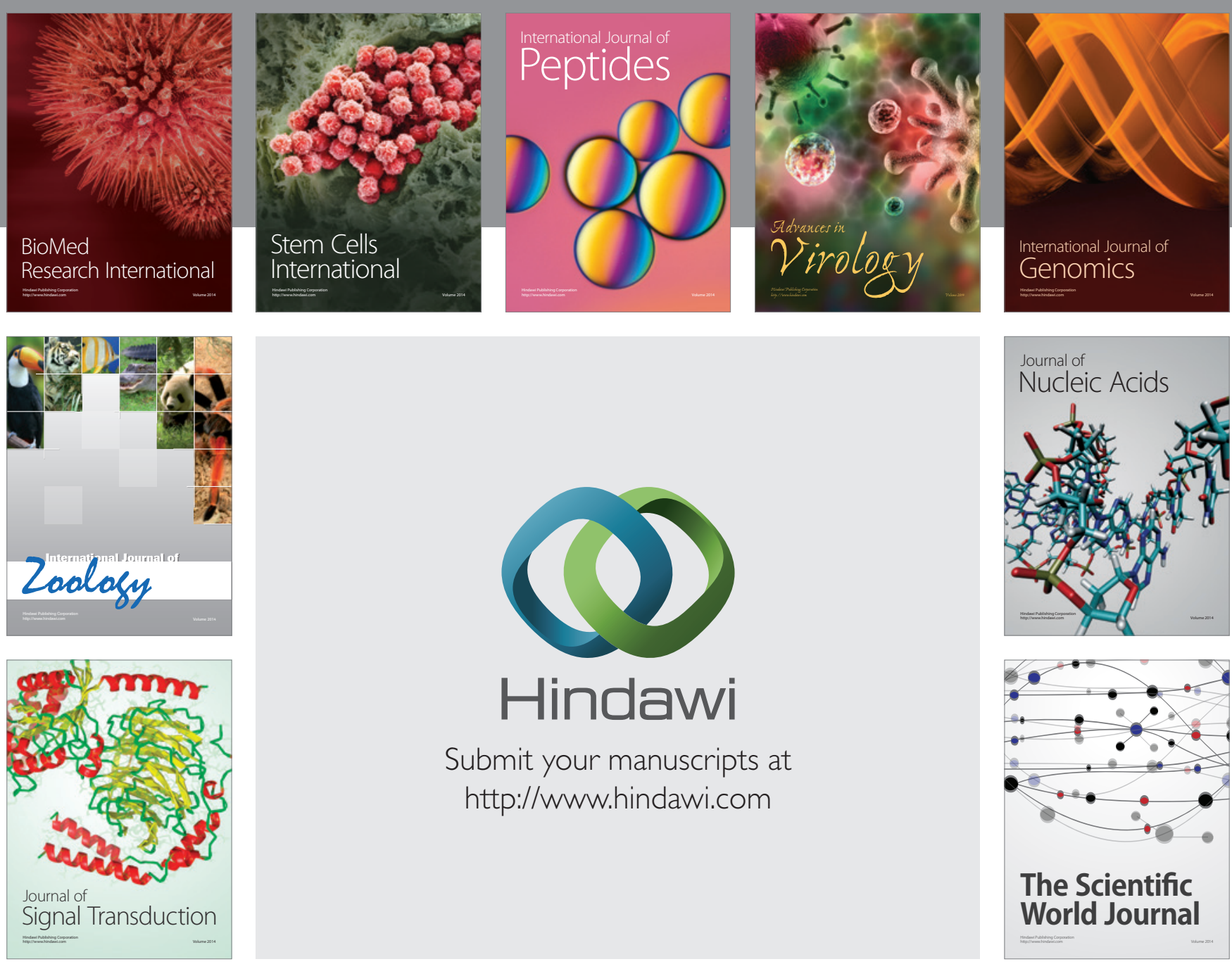

Submit your manuscripts at

http://www.hindawi.com
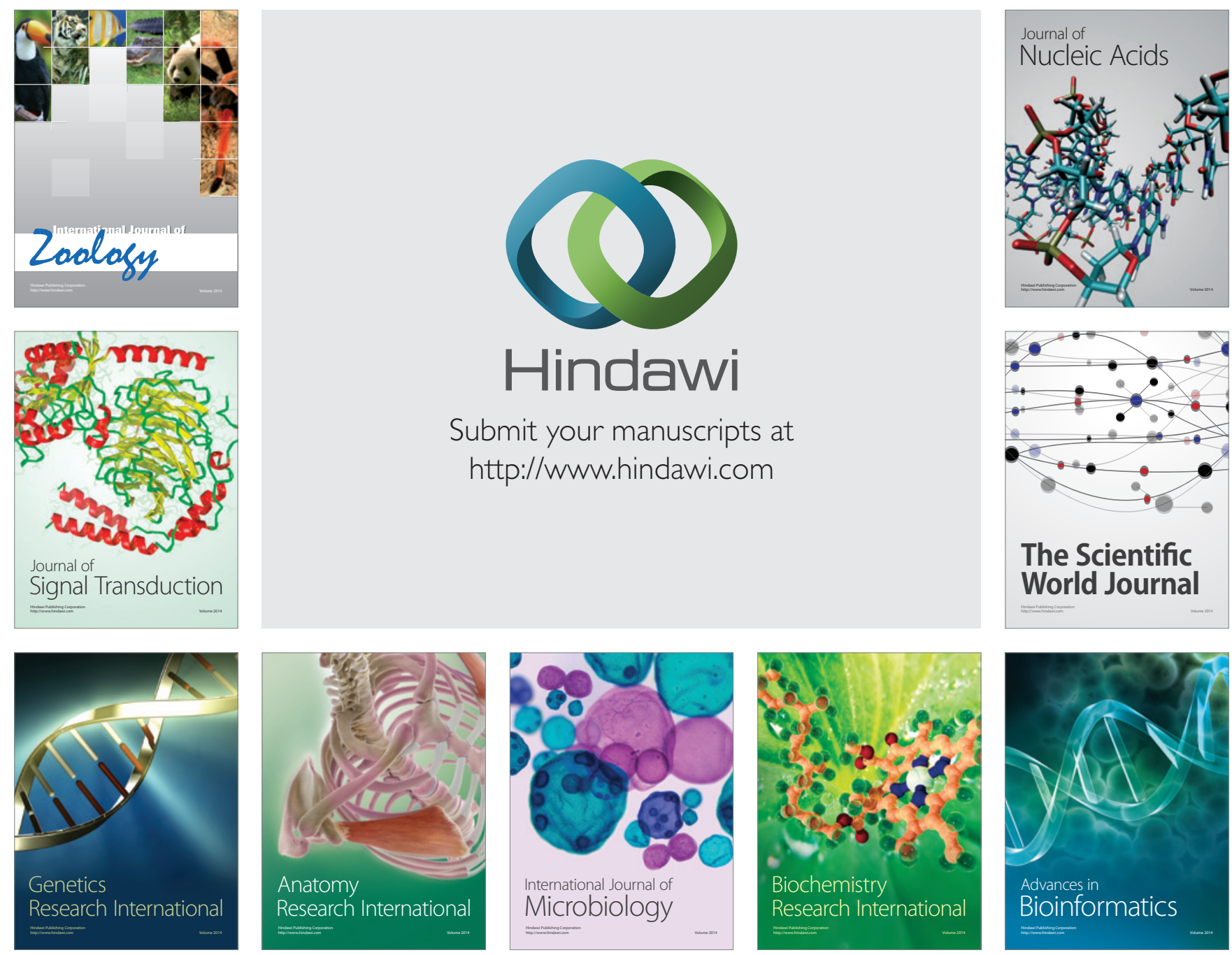

The Scientific World Journal
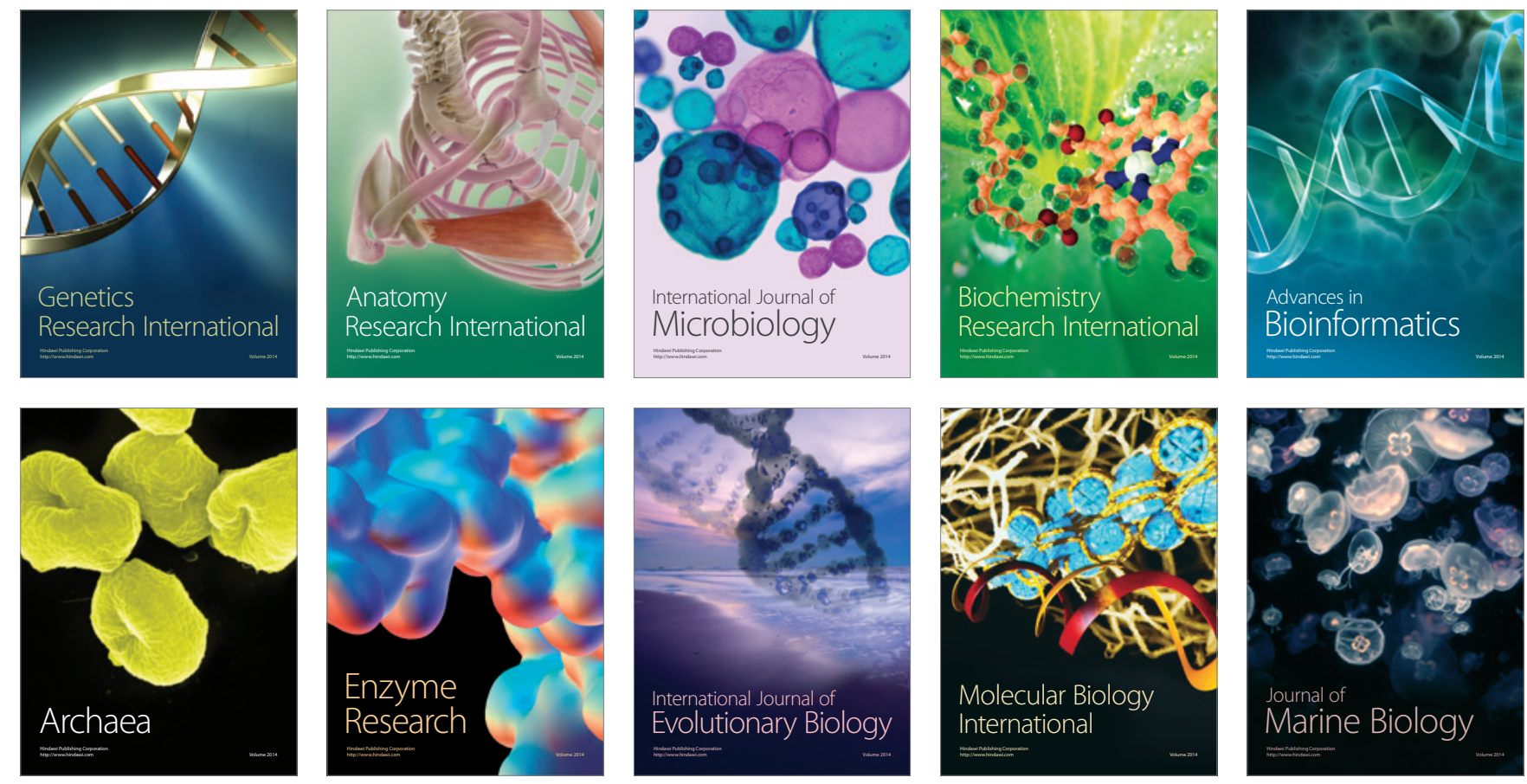